\title{
Depression and cancer treatment outcomes in African American and Caucasian cancer patients: A chart review study
}

\author{
Amy Zhang \\ Frances Payne Bolton School of Nursing, Case Western Reserve University, United States \\ Correspondence: Amy Zhang. Address: Frances Payne Bolton School of Nursing, Case Western Reserve University, \\ 10900 Euclid Avenue, Cleveland, OH 44106-4904, United States. Email: axz16@case.edu \\ Received: August 4, 2013 \\ Accepted: September 5, 2013 \\ Online Published: September 11, 2013 \\ DOI : $10.5430 /$ cns.v1n4p69 \\ URL: http://dx.doi.org/10.5430/cns.v1n4p69
}

\begin{abstract}
Objective: Depression is a significant predictor of cancer death, but its impact on African Americans' cancer treatment and treatment outcomes has not been well studied. This study examines the relationship between depression treatment, completion of cancer treatment, and treatment outcomes among African American cancer patients in comparison with Caucasian cancer patients in Northeast Ohio.

Methods: Medical records for 34 depressed breast and prostate cancer patients (18 African Americans and 16 Caucasians) with duration of 5 to 8 years were reviewed. Data on the variables of baseline distress level, depression treatment status, completion of prescribed cancer treatment, and treatment outcome (i.e., cancer recurrence, metastasis, and death) were abstracted. Simple statistics (frequency) was performed on these variables for the African American and Caucasian patients that received depression treatment and those who did not, respectively.

Results: In the study group, $30 \%$ of the African Americans with elevated baseline distress ( $\geq 4$ on a 10-point Distress Thermometer) were treated for depression, as compared to $60 \%$ of the Caucasians. Three of five African Americans that reduced or discontinued chemotherapy or hormonal therapy did not receive depression treatment. At 5 to 8 years after an initial cancer diagnosis, two of the African Americans, one treated and the other untreated for depression, both had cancer recurrence. Another untreated African American in the study developed metastasis and then died. By contrast, none of the African Americans treated for depression developed metastasis or died.

Conclusions: The findings suggest that under treatment of depression was associated with poor cancer treatment completion and treatment outcomes, especially in the African American group. Improving depression treatment of these patients deserves serious attention in future research.
\end{abstract}

\section{Key words}

Depression, Cancer, Treatment compliance, Survival, Cancer disparity

\section{I ntroduction}

In the United States, cancer mortality is 32\% higher in African American men and 16\% higher in African American women than in their Caucasian counterparts ${ }^{[1]}$. Disparity in cancer mortality exists for both late and early stages of cancer. 
The shorter survival for African Americans is mainly attributed to barriers to and disparities of cancer treatment when diagnosed early ${ }^{[1]}$.

Depression significantly predicts cancer mortality ${ }^{[2-4]}$. Evidence suggests that depression triples the likelihood of treatment nonadherence because it undermines comprehension of treatment options, motivation to treat, and ability to comply ${ }^{[3]}$. Incompletion of cancer treatment is conducive to cancer progression and worsening outcomes. Studies show that African Americans are less likely than Caucasians to adhere to adjuvant therapy ${ }^{[4]}$, making cancer death more likely ${ }^{[1]}$. However, the prevalence of depressive disorders in African American cancer patients has not been well established ${ }^{[5]}$. Studies of the impact of depression on African Americans' adherence to cancer treatment are nearly nonexistent.

Therefore, a retrospective chart review study was conducted for African American cancer patients with depression. The medical chart data on cancer treatment completion, cancer progression, and treatment outcome were collected and compared between African American cancer patients who received antidepressants and those who did not. The purpose was to assess whether there is a relationship between depression treatment and the completion of cancer treatment as well as treatment outcomes. African American cancer patients were also compared to Caucasian cancer patients on these variables to ascertain if this relationship is similar or different across racial groups.

\section{Methods}

Patients for this study were selected from a previously conducted study funded by the National Cancer Institute. The parent study was carried out from 2007 to 2009 to investigate the lived depressive experience of African American cancer patients in comparison with Caucasian cancer patients. Subject eligibility included a diagnosis of early-stage (I-III) breast or prostate cancer within the past 3 years, having completed cancer treatments for at least 6 months, and not having a psychotic disorder. The parent study enrolled 34 depressed African American and 17 depressed Caucasian cancer patients that had completed cancer treatment between 6 and 36 months in duration. The main criterion that was used to determine depression status was the cut-off score $(\geq 16)$ of the Center for Epidemiologic Studies Depression Scale (CES-D). The details of subject recruitment, identification of depression, and study design were published elsewhere ${ }^{[6]}$.

The chart review study reported herein was conducted in 2012 in Northeast Ohio. Of the enrolled subjects in the parent study, 18 depressed African American and 16 depressed Caucasian subjects had complete medical records available at a participating hospital and these medical records were reviewed. With institutional review board's approval, an experienced oncology nurse reviewed all documents in the medical records, including physician orders and notes, and abstracted the following variables: (a) the baseline distress score that was measured on a 0-10 Distress Thermometer, with 10 being the most distressed; (b) documented antidepressant treatment; (c) the percentage of dose completion and days of delay of cancer treatment, including chemotherapy, radiation therapy, and hormonal therapy; and (c) treatment outcomes, including cancer recurrence, metastasis, and cancer death as documented in the medical chart. The abstracted data were entered into an Excel spreadsheet and then converted to SPSS 19.0 software. Study subjects were classified into one of the two groups: having received antidepressant treatment, and having not received it. Descriptive statistics were performed to examine the mean and frequency of appropriate variables by the depression treatment status for African American and Caucasian patients, respectively.

\section{Results}

The African American and Caucasian groups were similar in age, gender, cancer treatment, and comorbidity. They showed some across-group variations in marital status, education, income, employment, and a depression diagnosis prior to cancer, but t-test, Chi-square test and the Fisher's exact test were unable to detect a statistical difference on any of these 
variables, likely due to a low statistical power. The $p$ values and effect size for the group comparisons are presented in Table 1.

Table 1. Sample demographics

\begin{tabular}{|c|c|c|c|c|c|c|}
\hline \multirow{2}{*}{ Variable } & \multicolumn{2}{|c|}{$\begin{array}{l}\text { Depressed African } \\
\text { Americans (n=18) }\end{array}$} & \multicolumn{2}{|c|}{$\begin{array}{l}\text { Depressed Caucasians } \\
(n=16)\end{array}$} & \multirow[t]{2}{*}{ Effect Size $^{*}$} & \multirow[t]{2}{*}{$P^{\#}$} \\
\hline & $\mathrm{N}$ & $\%$ & $\mathrm{n}$ & $\%$ & & \\
\hline Age in years $(m / s . d)$. & 60 & 10 & 57 & 10 & .23 & .51 \\
\hline Gender & & & & & .10 & .70 \\
\hline Female & 14 & 78 & 11 & 69 & & \\
\hline Marital status & & & & & .42 & .20 \\
\hline Married & 6 & 33 & 10 & 63 & & \\
\hline Single & 4 & 22 & 3 & 19 & & \\
\hline Other (widowed, divorced etc.) & 8 & 44 & 3 & 19 & & \\
\hline Education & & & & & .51 & .07 \\
\hline$\leq$ High school & 8 & 44 & 2 & 12 & & \\
\hline Some college & 8 & 44 & 6 & 38 & & \\
\hline$\geq$ College & 2 & 11 & 8 & 50 & & \\
\hline Employment & & & & & .29 & .23 \\
\hline Full time & 4 & 27 & 3 & 60 & & \\
\hline Half time & 0 & 0 & 1 & 20 & & \\
\hline Unemployed & 9 & 60 & 1 & 20 & & \\
\hline Unknown & 2 & 13 & 0 & 0 & & \\
\hline Income (optional) & & & & & .53 & .15 \\
\hline$<\$ 25000$ (household) & 6 & 33 & 0 & 0 & & \\
\hline$<\$ 50,000$ & 6 & 33 & 4 & 25 & & \\
\hline$\geq \$ 50,000$ & 3 & 17 & 7 & 44 & & \\
\hline Unknown & 3 & 17 & 5 & 31 & & \\
\hline Had surgery & 10 & 56 & 9 & 56 & .29 & .60 \\
\hline Had radiation & 13 & 72 & 11 & 69 & .36 & .23 \\
\hline Had chemotherapy & 7 & 39 & 6 & 43 & .29 & .62 \\
\hline Number of chronic diseases $\geq 3$ & 14 & 78 & 11 & 69 & .43 & .06 \\
\hline Prior depression diagnosis & 6 & 33 & 1 & 6 & .33 & .09 \\
\hline
\end{tabular}

Note. *: Cramer's V for categorical variables; Cohen's d for variable "age"

$\#$ : p for Chi-square test, Fisher's exact test or t-test

The chart review of the 34 study subjects (18 depressed African Americans and 16 depressed Caucasians) showed that 10 of the African American and 5 of the Caucasian patients had elevated distress at baseline following a cancer diagnosis with a score $\geq 4$ on a 10-point Distress Thermometer, which is a well-established cut off score for cancer patient's distress ${ }^{[7]}$. However, 3 of the 10 African Americans (30\%) with elevated baseline distress were treated for depression, as compared to 
3 of the 5 Caucasians (60\%). Overall, 8 of the 18 depressed African Americans (44\%) and 9 of the 16 depressed Caucasians (56\%) in the study had used antidepressant medication since receiving the cancer diagnosis.

As Table 2 shows, two African American and two Caucasian patients each took a dose of chemotherapy less than the prescribed amount, and only one of them (50\%) in each racial group received depression treatment. Three of the African Americans reduced or discontinued the dose of hormonal therapy; however, two of the three $(67 \%)$ were not treated for depression. On the other hand, two of the Caucasian patients treated for depression and two who were untreated for depression reduced or discontinued the dose of hormonal therapy. A Caucasian patient who was not treated for depression also reduced the dose of radiation therapy. Of the study subjects who had reduced or discontinued cancer treatment, three delayed chemotherapy or hormonal therapy. Additionally, one African American who was not treated for depression also delayed chemotherapy, but subsequently completed it in full dose.

At 5 to 8 years after a cancer diagnosis in 2012, two subjects treated for depression (one Caucasian and one African American) and an African American untreated for depression experienced cancer recurrence. Further, a Caucasian subject treated for depression developed cancer metastasis, and an African American untreated for depression also had cancer metastasis and subsequently died. By contrast, none of African American subjects who received depression treatment developed cancer metastasis or died. The chart review identified that four out of five subjects with cancer recurrence or metastasis had either reduced or delayed cancer treatment.

Table 2. Chart review results

\begin{tabular}{|c|c|c|c|c|}
\hline \multirow[b]{2}{*}{ Variables } & \multicolumn{2}{|c|}{ African Americans $(n=18)$} & \multicolumn{2}{|c|}{ Caucasians (n=16) } \\
\hline & $\begin{array}{l}\text { Treated for } \\
\text { depression } \\
(n=8)\end{array}$ & $\begin{array}{l}\text { Not treated } \\
\text { for depression } \\
(n=10)\end{array}$ & $\begin{array}{l}\text { Treated for } \\
\text { depression } \\
(\mathrm{n}=9)\end{array}$ & $\begin{array}{l}\text { Not treated } \\
\text { for depression } \\
(n=7)\end{array}$ \\
\hline & n (\%) & n (\%) & n (\%) & n (\%) \\
\hline \multicolumn{5}{|c|}{ Dose reduced /discontinued } \\
\hline Chemotherapy & $1(13 \%)$ & $1(10 \%)$ & $1(11 \%)$ & $1(14 \%)$ \\
\hline Hormonal Therapy & $1(13 \%)$ & $2(20 \%)$ & $2(22 \%)$ & $2(29 \%)$ \\
\hline Radiation & 0 & 0 & 0 & $1(14 \%)$ \\
\hline \multicolumn{5}{|l|}{ Dose delayed } \\
\hline Chemotherapy & 0 & $1(10 \%)$ & $1(11 \%)$ & 0 \\
\hline Hormonal Therapy & $1(13 \%)$ & 0 & $1(11 \%)$ & 0 \\
\hline Cancer recurrence & $1(13 \%)$ & $1(10 \%)$ & $1(11 \%)$ & 0 \\
\hline Metastasis & 0 & $1(10 \%)$ & $1(11 \%)$ & 0 \\
\hline Cancer death & 0 & $1(10 \%)$ & 0 & 0 \\
\hline
\end{tabular}

\section{Discussion}

Chart review results suggest that both the African American and Caucasian patients in the study had either reduced or discontinued cancer treatment or delayed cancer treatment irrespective of receiving depression treatment. However, a more careful examination revealed that when comparing to the group that received depression treatment, the group that had not received depression treatment contained one more African American and one more Caucasian that had reduced or discontinued cancer treatment. The implication is that a lack of depression treatment in these cancer patients may be associated with failure to complete their cancer treatments on schedule. 
Moreover, three African Americans (17\%) and two Caucasians (13\%) in the study experienced cancer recurrence and metastasis, but among the African Americans in the study group, cancer progression occurred more often in those who were not treated for depression. In fact, two of the three African Americans with cancer recurrence or metastasis were not treated for depression, and one of the two suffering from cancer metastasis died. The fact that four of five subjects in the study experiencing cancer recurrence or metastasis did not complete cancer treatments supports the notion that completion of treatment is critically important for cancer control and survival outcome. If reduced depression is associated with an increased ability and motivation to complete cancer treatment, then adequate treatment of depression is likely to improve survival outcome in cancer patients.

It is noteworthy that half as many African Americans as Caucasians in the study group with elevated baseline distress ( $\geq 4$ on a Distress Thermometer) had ever received depression treatment. Although $44 \%$ of the African Americans $(n=8)$ and $56 \%$ of the Caucasians $(n=9)$ eventually were treated for depression, the likelihood that the African American patients receive depression treatment could have been improved if they had been treated the same as their Caucasian counterparts on the basis of baseline distress scores from the beginning.

\section{Conclusions}

This chart review study describes a pattern of under treatment for depression and its possible association with poor cancer treatment adherence and outcome in cancer patients. Although the findings are based on a limited number of case reviews, they suggest that inadequate treatment for depression and adverse consequences were evidential in all cancer patients and particularly problematic in the African American group. Thus, providing adequate depression treatment would be important for improving cancer treatment and treatment outcomes, especially among African American cancer patients.

Caution is warranted in the interpretation of the chart review results. The study sample is too small to suggest statistic likelihood of receiving depression treatment or cancer treatment outcome. The findings may be unreliable because it is uncertain whether the observed effect indicates a trend or is simply random. The data taken from medical charts are retrospective and may not be complete. This potential problem can bias the chart review outcome. Thus, these findings should be considered preliminary. Because of the significance of this topic, it is important to replicate this study in a larger sample of African American cancer patients. Future research needs to pay more attention to the treatment of depression and its impact on cancer disparity and survival.

\section{Disclosure}

The author does not have a direct financial relation with the commercial identities (SPSS Inc.) or any conflict of interest for the production of this article.

\section{References}

[1] American Cancer Society. Cancer Facts \& Figures for African Americans 2011-2012. Atlanta, GA: American Cancer Society, Inc. 2012.

[2] Onitilo AA, Nietert PJ, Egede LE. Effect of depression on all-cause mortality in adults with cancer and differential effects by cancer site. Gen Hosp Psychiatry. 2006; 28(5): 396-402. PMid:16950374 http://dx.doi.org/10.1016/j.genhosppsych.2006.05.006

[3] Pinquart D. Depression and cancer mortality: a meta-analysis. National Institutes of Health Psychology Medicine. 2010; 40(11): 1797-1810.

[4] Satin JR, Linden W, Phillips MJ. Depression as a predictor of disease progression and mortality in cancer patients: a meta-analysis. Cancer. 2009; 115(22): 5349-61. PMid:19753617 http://dx.doi.org/10.1002/cncr.24561

[5] Aziz NM, Rowland JH. Cancer survivorship research among ethnic minority and medically underserved groups. Oncology Nursing Forum. 2002; 29(5): 789-801. PMid:12058154 http://dx.doi.org/10.1188/02.ONF.789-801

[6] Zhang AY, Gary F, Zhu H. What precipitated depression in African American cancer patients? Triggers and stressors. Palliative \& Supportive Care. 2012; 10(4): 279-286. PMid:22436086 http://dx.doi.org/10.1017/S1478951511000861

[7] Holland et al. NCCN Clinical Practice Guidelines in Oncology (NCCN Guidelines): Distress Management. Version 2.2013, National Comprehensive Cancer Network, Inc. 2013. 